\title{
Analysis of change in material composition due to machining
}

\author{
Rahul Chadhokar ${ }^{1}$, Ashok Atulker $^{2}$ \\ ${ }^{1,2}$ SGSITS, 23 Park Road, Indore
}

\begin{abstract}
In fact it is, no doubt watched that while machining when chips shaping happen high measure of hotness is created because of shearing movement of chips and the contact demonstrations between chip surface and workpiece surface and in addition it assume its part on instrument surface and chip surface. Because of high bring up in temperature, blazing of carbon particles happen hence the synthesis of carbon substance of workpiece surface and chips shifts which is reflected by the different colors of chips. In this paper the study have been carried out for figuring the change in carbon content because due to different depth of cut during machining.
\end{abstract}

\section{Introduction}

Machining or metal removal techniques are generally utilized in industry for the creation of variety of engineering products. Conventional machining operation, for example, turning, milling, and drilling etc. remove material through a shearing process. Throughout these methodologies a great measure of vitality changed over into hotness because of shearing activity and friction between parts. Heat has discriminating impacts on machining. To some extent, it can increase tool wear and then reduce tool life, get rise to thermal deformation and cause to environmental problems, etc.[1]

Steel is a crystalline composite of iron, carbon and a few different components it hardens when quenched above its critical temperature. It contains no slag and may be cast, rolled, or forged. Carbon is a critical constituent due to its capacity to build the hardness and the quality of the steel. Steel is arranged as stated by the alloying components it hold and consequently all steels are characterized as stated by carbon content. Plain carbon steels hold fundamentally compound of iron and carbon in which carbon fluctuates from follow to about two percent by weight.[2]

\section{Literature survey:}

Research on effect of machining parameter:

Effect of various machining parameters on surface roughness are studied with the help of full factorial design of experiments (DOE) and determined the best combination of machining parameters such as depth of cut, feed and cutting speed. It is observed from the ANOVA that feed $(60.85 \%)$ is the most significant parameter followed by cutting speed $(24.6 \%)$ and the two level interactions were also found to be significant between cutting speed feed $(6.23 \%)$ and depth of cut-feed $(2.62 \%)$ on surface roughness. From the experimentation it is found that, depth of cut did not impact the surface roughness in the studied range, significantly. The most optimal results for surface roughness were observed when cutting speed was set at $150 \mathrm{~m} / \mathrm{min}$ and feed of 0.05 $\mathrm{mm} / \mathrm{rev}$. The present research work on turning of hardened AISI 340 steel with CVD multilayer coated carbide insert will be useful for the advanced engineering industries those are working in the field of precision machining.[3]

BUE formation on the cutting tool caused an increase in the tool nose radius on the cutting tool surface. This BUE formation at lower cutting speeds $(200 \mathrm{~m} / \mathrm{min})$ positively affected the surface roughness. BUE and BUL formed at greater amounts on the surface of the cutting tool at $200 \mathrm{~m} / \mathrm{min}$ and $300 \mathrm{~m} / \mathrm{min}$ cutting speeds, whereas BUE and BUL formation was observed at lesser amounts at $400 \mathrm{~m} / \mathrm{min}$ and $500 \mathrm{~m} / \mathrm{min}$ cutting speeds. Maximum BUE and BUL formation occurred during the machining process at $200 \mathrm{~m} / \mathrm{min}$ cutting speed. 500 $\mathrm{m} / \mathrm{min}$ and higher cutting speeds were determined for the selection of cutting speed to prevent BUE and BUL formation when machining AA2014 (T4) alloy with an uncoated seventieth carbide cutting tool. The minimum cutting force depending on the cutting speed and feed rate $(137 \mathrm{~N})$ was determined at $500 \mathrm{~m} / \mathrm{min}$ cutting speed and $0.10 \mathrm{~mm} / \mathrm{rev}$. in this study. The maximum cutting force value $(390 \mathrm{~N})$, on the other hand, was determined at $200 \mathrm{~m} / \mathrm{min}$ cutting speed and $0.30 \mathrm{~mm} / \mathrm{rev}$ feed rate. The minimum average surface roughness value $(0.93 \mu \mathrm{m})$ was determined at $500 \mathrm{~m} / \mathrm{min}$ cutting speed and $0.10 \mathrm{~mm} / \mathrm{rev}$ feed rate in this experimental study. The maximum average surface roughness value $(5.34 \mu \mathrm{m})$, on the other hand, was determined at $300 \mathrm{~m} / \mathrm{min}$ cutting speed and $0.30 \mathrm{~mm} / \mathrm{rev}$ feed rate.[4] 


\section{Research on temperature effect on material}

The impact of cutting temperature, especially when it's high, is generally impeding to both the tool and the workpiece. Attempt must therefore be made, for adequate monitoring of this temperature during machining so as to improve the cutting tool life during ant machining operation. The accompanying is a portion of the results of high cutting temperature on both the cutting instrument and workpiece:

1. Rapid tool wear, which reduce tool life

2. Plastic deformation of the cutting tool life

3. Thermal flaking and fracturing of the cutting edges due to thermal shocks

4. Built up edge formation

5. Surface damage by oxidation and rapid corrosion

6. Induction of tensile residual stresses and micro cracks as the surface.[2]

\section{Research on burning of carbon in presence of oxygen:}

The outcomes of this work included both qualitative and quantitative evaluation of the oxide scale shaped on the five steel reviews in a heater burning item climate at $1100^{\circ} \mathrm{c}$ with diverse stack oxygen focuses and oxygen enhancement levels. The qualitative outcomes are exhibited as hedonic rankings, backed by photographic confirmation, for the scale aspects and photomicroscope and SEM dissection of specimens at chose oxidation conditions. In the present work, the steel specimens entered the heater in a "cool" state (surrounding research center temperature) and arrived at the heater temperature inside a 5 minute period. The exothermic high temperature impact connected with the scaling responses might result in a transient temperature spike in the scale and steel substrate. This transient might equilibrate to the heater temperature in about the same time period. Thus scaling rates for the early phases of the steel specimen warming procedure might not yield advantageous data. In the present work, the examples were laid open to heater gas environments for a base time of 30 prior minutes specimens were concentrated from the heater for analysis.[5]

During the steelmaking process, some of the iron can itself become "burned" or oxidized to the point where it adds to the percentage of molten iron oxide in the liquid slag phase which co-exists in the furnace with the metal. If the steelmaker makes a mistake and fails to stop the oxygen "blow" at the desired "end-point" of impurity oxidation, the oxidation of iron can become excessive. This will show up as a measurable yield loss of iron to the slag, giving predictable, calculable, higher concentrations of molten iron oxide $(\mathrm{FeO})$ in slag. To the steelmaker, there is no mystery about what happens when iron burns. Once the carbon is gone (oxidized to CO), any additional oxygen combines with the iron to produce $\mathrm{FeO}$ into the slag.[6]

\section{Strohlein Apparatus:}

\section{Methodology:}

Strohlein (carbon \& sulfur device) self-loader contraption is utilized to distinguish carbon and sulfur content in iron and steel. The scale of device burette is directly calibrated in terms of carbon percentage. The apparatus can locate carbon rate up to $4.5 \%$. By utilizing exchangeable burettes, the estimation could be taken to $0.25 \%, 0.5 \%, 1.5 \%$ and $4.5 \%$. The apparatus furnace attains required temperature rapidly and a high accuracy digital pyrometer indicates the furnace temperature. The equipment can detect carbon or sulphur or both.

Glass parts gathering comprise of carbon burette, three-way stopcock, " $t$ " straight stopcock, gas Cooling snaked condenser, leveling counter set, leveling container, sulfur burette, sulfur bubbler, Gas washing jugs, channel trap, perception tube, "l" \& "u" glass twists, thermometer 0-500c fitted On stand . (Without substance \& reagents)

Tube heater minimized \& light in weight protected with widely acclaimed earthenware fiber, having the Total length in the middle of 390 to $410 \mathrm{~mm}$ fitted with silicon carbide warming components to give 660watts to attain temp up to 13500 c in brief time through venture down transformer fitted in the Separate control board, temperature sensor of respectable metal pt-pt-rh to suit working Ceramic container of $24 \mathrm{~mm}$ o.d. Specifically mountable on control board to maintain a strategic distance from back weight throughout operation.

Control board comprising of venture down above transformer to administer the 660 wattage least Of the tube heater, fitted with advanced temperature pointer with headed presentation for temperature Sensor, ammeter, wellbeing switch showing lights and on off switch and to be utilized as stand for tube heater.

\section{Principle:}

In the event that steel chips are blazed in $\mathrm{O}_{2}$ at something like $1200^{\circ} \mathrm{c}$ then $\mathrm{CO}_{2}$ is framed, if this gas mixture is taken into a vessel of known volume. And after that passed through an answer of $\mathrm{KOH}$ which with absorb $\mathrm{CO}_{2}$ and afterward remaining gasses are brought once more to the carbon burette vessel and these volume noted. The contrast will give the volume of $\mathrm{Co}_{2}$ assimilated. On the off chance that now scale is balanced is perused straightforwardly \% of carbon then we get contact of the example under test. 


\section{Preparation of test sample:}

\section{Experimentation and calculation:}

For sample preparation mild steel cylindrical bar is taken. First surface grinding is done on grinding machine for removing the surface rust from the work piece. Then surfacing of the work piece is done for flattening of the surface to make a constant material removal during turning. Then the turning operation is applied and chips are collected. The material is removed using different depth of cut like for 0.5, 1.0, 1.5, 2.0 $\mathrm{mm}$. respectively. With maintaining the feed rate of $0.051 \mathrm{~mm} /$ revolution and speed is maintained $224 \mathrm{rpm}$ for $0.5,1.0, \& 1.5 \mathrm{~mm}$ depth of cut and $140 \mathrm{rpm}$ for $2.0 \mathrm{~mm}$ depth of cut. Then sample specimens are prepared by weighting the sample.

\section{Testing on mild steel specimen for different depth of cut:} calculation

The testing of material of known carbon contain is necessary for finding correction factor for the

Correction factor $=\frac{\text { carbon percentage of known material }}{\text { carbon percentage testd at atmophiric condition }}$

Correction factor $=\frac{0.21}{0.20}=1.05$

Now the sample is tested of different depth of cut on the room temperature and pressure.

Where,

$$
\mathrm{C}_{1}=\mathrm{C}_{2} / \mathrm{W} \times[\text { correction factor }]
$$

$\mathrm{c} 1=$ carbon content as readied on scale at $16^{\circ} \mathrm{c}$ and $760 \mathrm{~mm}$ pressure.

$\mathrm{c} 2=$ calculated content at room temperature and atmospheric pressure.

$\mathrm{w}=$ weight of sample (in $\mathrm{gm})$

1. $0.5 \mathrm{~mm}$ depth of cut:

Calculated carbon content $=0.095$

Weight of sample $=0.5 \mathrm{gm}$.

$\mathrm{C}_{0.5}=\frac{0.095}{0.5} \times 1.05=0.1995 \%$

2. $1.0 \mathrm{~mm}$ depth of cut:

Calculated carbon content $=0.085$

Weight of sample $=0.5 \mathrm{gm}$.

$\mathrm{C}_{1.0}=\frac{0.085}{0.5} \times 1.05=0.1785 \%$

3. $1.5 \mathrm{~mm}$ depth of cut:

Calculated carbon content $=0.145$

Weight of sample $=1.0 \mathrm{gm}$.

$\mathrm{C}_{1.5}=\frac{0.145}{1.0} \times 1.05=0.15225 \%$

4. $2.0 \mathrm{~mm}$ depth of cut:

Calculated carbon content $=0.12$

Weight of sample $=1.0 \mathrm{gm}$.

$\mathrm{C}_{2.0}=\frac{0.12}{1.0} \times 1.05=0.126 \%$

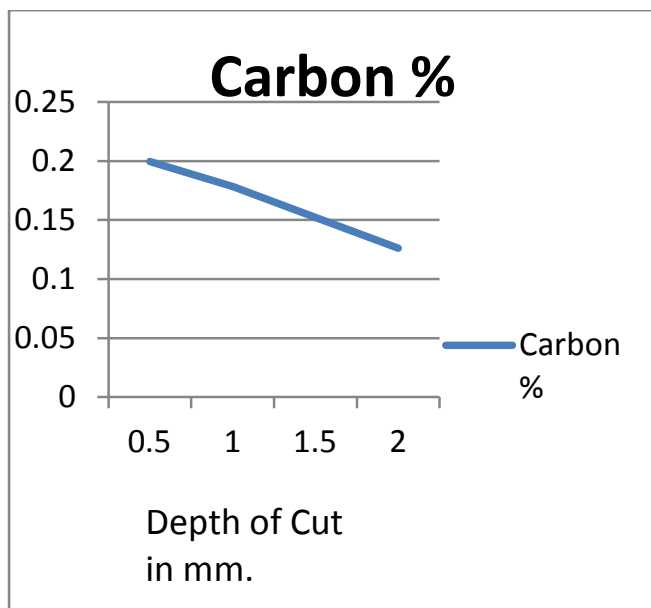




\section{Conclusion}

It has been observed from the experimental data and calculation that due to increase in depth of cut, temperature of the contact zone has increased which caused the high burning of carbon particles present in the material at that level as shown in the above graph and using experimental data the correction factor has been calculated for generalizing the phenomenon, although the exact value of correction factor up to decimal level can be calculated using well defined and controlled experimental conditions under the perfect set up of Strohlein Apparatus.

\section{References:}

[1]. Yuliu Zheng, John W. Sutherland and Walter W. Olson, A predictive heat generation modal in orthogonal cutting visco-plastic material, Vol. 6, No. 3, 1996.

[2]. Ajiboye, Tajudeen kolawole, Determination of cutting force and temperature change in heat treated mediam carbon steel during lathe turning process.

[3]. Sudhansu Ranjan Das, Amaresh Kumar, and Debabrata Dhupal, Effect of machining parameters on surface roughness in machining of hardned AISI 4340 steel using coated carbide inserts, International Journal of Innovation and Applied Studies ISSN 2028-9324 Vol. 2 No. 4 Apr. 2013, pp. 445-453.

[4]. Hasan Gökkaya, the Effects of Machining Parameters on Cutting Forces, Surface Roughness, Built-Up Edge (BUE) and Built-Up Layer (BUL) During Machining AA2014 (T4) Alloy, Strojniški vestnik - Journal of Mechanical Engineering 56(2010)9, $584-593$.

[5]. D. Poirier, E.W. Grandmaison, M.D. Matovic, K.R. Barnes and B.D. Nelson, High Temperature Oxidation of Steel in an Oxygenenriched Low $\mathrm{NO}_{X}$ Furnace Environment, IFRF Combustion Journal Article Number 200602, September 2006 ISSN 1562-479X.

[6]. Michael D. Lanyi, Discussion on Steel Burning in Oxygen, Flammability and Sensitivity of Materials in Oxygen-Enriched Atmospheres: Ninth Volume, ASTM STP 1395. 